\title{
Relation Between Time and Temperature Dependence of Diffusion and the Structural State in ZrTiCuNiBe Bulk Glasses
}

\author{
Thomas Zumkley ${ }^{1}$, Volkmar Naundorf ${ }^{1}$, Michael-Peter Macht ${ }^{1}$, Peter Fielitz $^{1 *}$ \\ and Günter Frohberg ${ }^{2}$ \\ ${ }^{1}$ Department Materials Sciences, Hahn-Meitner-Institute Berlin, Glienicker Str. 100, D-14109 Berlin, Germany \\ ${ }^{2}$ Institute of Materials Sciences and Technology, Technical University Berlin, Hardenbergstr. 36, D-10623 Berlin, Germany
}

\begin{abstract}
Time and temperature dependence of impurity diffusion is measured in detail for several ZrTiCuNiBe bulk glasses in a wide temperature range. We find that neither the quenched-in free volume nor a small volume fraction of crystals have a significant effect on the diffusivity. It is shown that the composition of these glasses has a much weaker effect on the diffusion coefficients than have structural changes of the glass. By long time relaxation the reversible metastable equilibrium of the glass structure could be reached at temperatures below the calorimetric glass transition. For this metastable equilibrium state a single set of diffusion parameters, activation enthalpy and pre-factor of the diffusion coefficient, is derived in the entire temperature range above and below the glass transition. This indicates that the usually observed non-linear Arrhenius behavior of diffusion coefficients in the ZrTiCuNiBe bulk glasses is caused by insufficient structural relaxation at temperatures below the calorimetric glass transition.
\end{abstract}

(Received February 22, 2002; Accepted March 12, 2002)

Keywords: diffusion, structural state, long time relaxation, reversible metastable equilibrium, arrhenius behavior, zirconium based beryllium bearing bulk glass

\section{Introduction}

Metallic bulk glasses are multi-component alloys comprising at least four components. This new class of materials includes alloys of the PdCuNiP, $\mathrm{ZrCuNiAl}$ and $\mathrm{ZrTiCuNiBe}$ type $^{1-3)}$ and can be produced in bulky form because the crystallization is bypassed during solidification of the liquid melt at relatively low critical cooling rates which can be as low as $0.1 \mathrm{~K} / \mathrm{s}{ }^{1-4)}$ Metallic bulk glasses are stable, i.e. they resist the general tendency to crystallize in a wide temperature range above the glass transition for rather long times. Based on their favorable physical and mechanical properties and excellent processing capabilities metallic bulk glasses have considerable potential as advanced engineering materials for technical application. ${ }^{1-3,5)}$

ZrTiCuNiBe bulk glasses are prominent representatives and are well suited for fundamental investigations of these new materials. They can be rather easily produced at cooling rates of $1-20 \mathrm{~K} / \mathrm{s}$, which is generally sufficient to obtain rods with diameters up to $50 \mathrm{~mm}^{2,3)} \mathrm{Be}$, which is the smallest and most mobile atom in the alloy, seems to play a key role for the glass forming ability and the stability of the ZrTiCuNiBe-bulk glasses. ${ }^{6)}$ One of the best glass formers of the $\mathrm{ZrTiCuNiBe}$-family is the $\mathrm{Zr}_{41} \mathrm{Ti}_{14} \mathrm{Cu}_{12.5} \mathrm{Ni}_{10} \mathrm{Be}_{22.5}$ alloy (here called V1). ${ }^{7)}$ However, it is known that the V1 glass decomposes already at temperatures below $620 \mathrm{~K}$, i.e. near the calorimetric glass transition, within a few hours, ${ }^{8-11)}$ and isothermal crystallization of the undercooled melt starts after less than $1 \mathrm{~h}$ at $650 \mathrm{~K} .^{12)}$ The decomposition of $\mathrm{V} 1$ causes a nanosized microstructure of two phases, one of them enriched in $\mathrm{Be}$ and $\mathrm{Zr}$, and depleted of $\mathrm{Ti}$ and $\mathrm{Cu}$, the other enriched in $\mathrm{Ti}$ and $\mathrm{Cu}$, and depleted of $\mathrm{Be}$ and $\mathrm{Zr} .{ }^{13,14)}$ The two alloys, $\mathrm{Zr}_{41} \mathrm{Ti}_{8.7} \mathrm{Cu}_{12.5} \mathrm{Ni}_{10} \mathrm{Be}_{27.8}$ (here called D1) and

*Present address: Institute of Metallurgy, Technical University Clausthal, Robert-Koch-Str. 42, D-38678 Clausthal-Zellerfeld, Germany.
$\mathrm{Zr}_{41} \mathrm{Ti}_{16.5} \mathrm{Cu}_{12.5} \mathrm{Ni}_{10} \mathrm{Be}_{20}$ (here called D2), lie together with the V1 glass on a common line of the pseudo-ternary ( $\mathrm{Zr}, \mathrm{Ti})-$ $(\mathrm{Cu}, \mathrm{Ni})-\mathrm{Be}$ phase diagram and differ only in their Be/Ti ratio. ${ }^{15)}$

A higher Be-content is expected to improve the thermal stability of the ZrTiCuNiBe glasses. ${ }^{16,17)}$ In fact, the $\mathrm{Zr}_{46.8} \mathrm{Ti}_{8.2} \mathrm{Cu}_{7.5} \mathrm{Ni}_{10} \mathrm{Be}_{27.5}$ glass (here called V4) shows an exceptionally extended region of the supercooled liquid phase, with the calorimetric glass transition at $603 \mathrm{~K}$, and the first crystallisation at $730 \mathrm{~K}^{18)}$ Detailed investigations of the microstructure have revealed, however, the existence of a small fraction of primary crystals which could be identified as a modified $\mathrm{Be}_{2} \mathrm{Zr}$ phase. ${ }^{19)}$ These crystals can be observed by optical microscopy, but they cannot be detected in the $\mathrm{Cu}-\mathrm{K}_{\alpha}$ $\mathrm{X}$-ray diffraction (XRD) spectrum since generally their volume fraction is lower than about $3 \% .^{20}$ ) The number density of these primary crystals increases steeply with decreasing cooling rate. ${ }^{18)}$ Their formation during the production indicates general limitations of the glass forming ability of the ZrTiCuNiBe glasses.

Although the V4 glass is not the most stable of the ZrTiCuNiBe family ${ }^{17)}$ it is sufficiently stable in order to perform extended experiments in the supercooled liquid state below temperatures of about $670 \mathrm{~K}$ before a massive crystallization sets in. It is this property which makes the bulk glasses in general and the ZrTiCuNiBe glasses in particular attractive for fundamental investigations of the behavior of supercooled liquids, because the temperature range is now extended well above the calorimetric glass transition which was up to now not accessible with the conventional melt-spun glasses.

Most of the unavoidable structural changes of the metastable bulk glasses at higher temperatures, e.g. decomposition connected with the formation of other amorphous phases or crystallization, require long range atomic transport. Hence any interest in the static properties of state and stability 
of the glasses implies at the same time a fundamental interest in the dynamic property of diffusion. This paper reports on measurements of impurity diffusion around the calorimetric glass transition temperature in four $\mathrm{ZrTiCuNiBe}$ bulk glasses, namely the glasses V1, D1, D2, and V4. It focusses on the effects of composition and of time dependent structural changes on the diffusivity in these glasses. We use B, Fe, Co, Al, and $\mathrm{Hf}$ impurities as probes which in these glasses are in part chemically similar to the alloy components and cover their size spectrum, so that the behavior of these impurities ought to reflect self diffusion. The experimental details will be described in ch. 2. In ch. 3 we present the time and temperature dependent diffusion coefficients. A thorough discussion of these results in ch. 4 will show that diffusion in the ZrTiCuNiBe bulk glasses is strongly affected by at least two different structural changes which the glasses undergo during isothermal annealing in the supercooled liquid and amorphous state.

\section{Experimental Details}

Four alloys of the ZrTiCuNiBe family with different compositions, namely the alloys $\mathrm{Zr}_{41} \mathrm{Ti}_{14} \mathrm{Cu}_{12.5} \mathrm{Ni}_{10} \mathrm{Be}_{22.5}$ (V1), $\mathrm{Zr}_{41} \mathrm{Ti}_{8.7} \mathrm{Cu}_{12.5} \mathrm{Ni}_{10} \mathrm{Be}_{27.8}$ (D1), $\mathrm{Zr}_{41} \mathrm{Ti}_{16.5} \mathrm{Cu}_{12.5} \mathrm{Ni}_{10} \mathrm{Be}_{20}$ (D2), and $\mathrm{Zr}_{46.8} \mathrm{Ti}_{8.2} \mathrm{Cu}_{7.5} \mathrm{Ni}_{10} \mathrm{Be}_{27.5}$ (V4) were produced in the form of bulk glasses by levitation melting of the pure elements under purified Ar atmosphere, and cooling the melt by contact with a water cooled copper surface. Estimated cooling rates for these as-cast glasses range between $10 \mathrm{~K} / \mathrm{s}$ and $30 \mathrm{~K} / \mathrm{s}$. From the resulting ingots of oblate spherical shape (principle diameters: about $15 \mathrm{~mm}$ thick, $20 \mathrm{~mm}$ wide) plates of $10 \times 10 \times 1 \mathrm{~mm}^{3}$ were cut. Part of the V4 glass was remelted and splat cooled in order to obtain sample material which has undergone a considerably higher cooling rate estimated to about $10^{6} \mathrm{~K} / \mathrm{s}$. The surface of all these samples was mechanically polished to $1 \mu \mathrm{m}$ grade. The XRD spectrum of the specimens showed no indication of any crystalline peak. Inspection by optical microscopy showed, however, the presence of primary crystals with number densities of typically $10^{14} \mathrm{~m}^{-3}$ in the slowly cooled samples. DSC scans of the material indicated a reproducible state of the glass. XRD and DSC were generally also used in order to characterize the glass after diffusion and the various other annealing treatments.

The layer structure required for the diffusion measurements was prepared under ultra-high vacuum conditions in three steps. First the surface was cleaned by sputtering with $4 \mathrm{kV}$ Ar ions in order to remove any contaminations and oxides left over from the polishing procedure. Next a layer of about one nanometer thickness of the impurity to be investigated, i.e. $\mathrm{Hf}, \mathrm{Al}, \mathrm{Co}, \mathrm{Fe}$, and $\mathrm{B}$, was sputter deposited onto the surface. Finally a layer of the base material was sputter deposited on top of the specimens to protect the thin impurity layer. Each specimen was cut into four pieces of $5 \times 5 \mathrm{~mm}^{2}$. Only three of these were diffusion annealed so that the nonannealed reference state was always available for an evaluation of the penetration depth profiles. Generally the annealing was performed in a resistance furnace under vacuum better than $10^{-4} \mathrm{~Pa}$, annealing temperatures were controlled to better than $\pm 1.5 \mathrm{~K}$. Annealings for times shorter than $2000 \mathrm{~s}$ were performed in a differential scanning calorimeter (DSC,
Perkin Elmar Pyris 1).

The concentration depth profiles of the impurity atoms before and after annealing were obtained by sputter sectioning with $4 \mathrm{kV} \mathrm{O}_{2}^{+}$ions in combination with secondary ion mass spectrometry (SIMS). Details of this technique are given elsewhere. $^{21)}$ Figure 1 shows, as an example, depth profiles of $\mathrm{Al}$ in V4 glass before and after annealing for $2 \mathrm{~h}$ at $624 \mathrm{~K}$. For such measurements we assume that the intensity measured for the impurities by SIMS is proportional to their atomic concentration. ${ }^{22)}$ The width of the Al peak from the as-prepared state indicates a depth resolution of about $10 \mathrm{~nm}$ full width at half maximum which is characteristic of the SIMS technique when using $4 \mathrm{kV} \mathrm{O}_{2}^{+}$ions. The magnitude of this depth resolution results mainly from ion mixing and surface roughening due to the sputter process. ${ }^{23)}$ Broadening of the concentration depth profile due to diffusion of the $\mathrm{Al}$ is also visible in Fig. 1. The slight increase of the Ni matrix signal in the vicinity of the peak position is caused by an enhanced ionization probability in the layer region. ${ }^{21-23)}$

The design of the specimens satisfies the boundary conditions of the thin film solution of the diffusion equation. Hence the spatio-temporal evolution of the impurity concentration, $C(x, t)$, along the $x$-axis perpendicular to the thin layer originally positioned at $x_{0}$ is given by

$$
C(x, t)=A(\sqrt{\pi D t})^{-1} \exp \left(-\left(x-x_{0}\right)^{2} / 4 D t\right) .
$$

Here $A$ is the amount of originally deposited impurities, $D$ is the diffusion coefficient (assumed to be independent of time and concentration), and $t$ is the diffusion time. The diffusion coefficient can be determined from the slope $s$ of a plot of $\ln C$ vs. $\Delta x^{2}=\left(x-x_{0}\right)^{2}$ as

$$
D=\left(s^{-1}-s_{0}^{-1}\right) / 4 t \text {. }
$$

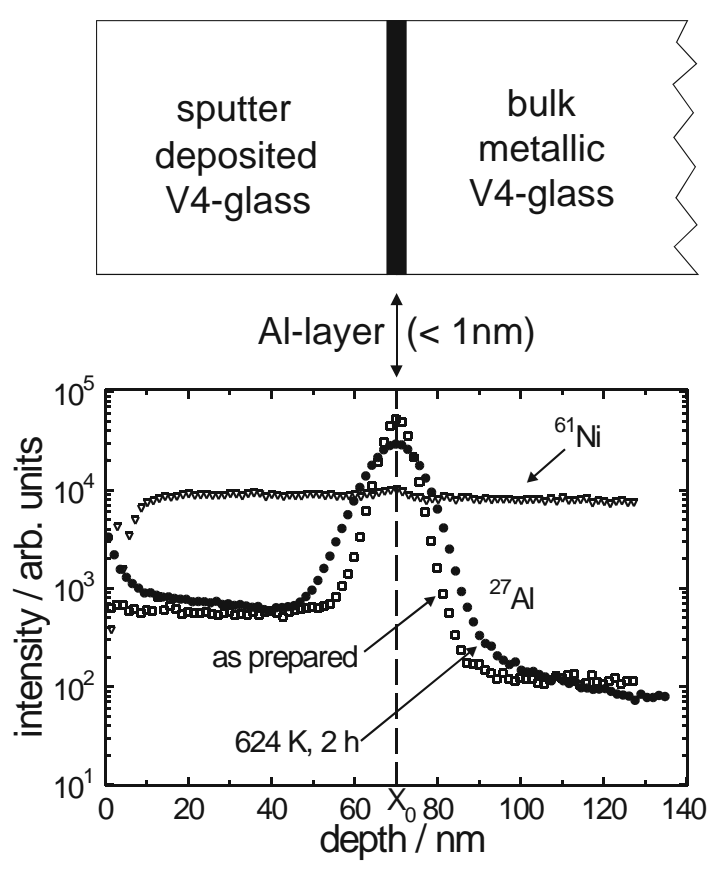

Fig. 1 Concentration depth profile as measured by sputter sectioning and secondary ion mass spectrometry (SIMS): sketch of the layer structure representing the diffusion sample (upper part), example of measured $\mathrm{Al}$ and $\mathrm{Ni}$ concentration depth profiles (lower part). Note the diffusional broadening of the $\mathrm{Al}$ layer after a $2 \mathrm{~h}, 624 \mathrm{~K}$ diffusion anneal. 
With $s_{0}$ in eq. (2) the instrumental broadening of the impurity profile (depth resolution of the SIMS technique) is taken into account. It is derived from the depth profile of the nonannealed reference specimen. If the diffusion coefficient depends on time as may happen, for instance, by structural changes (relaxation) of the material in the course of the diffusion anneal, then eqs. (1) and (2) remain valid when $D$ is replaced by the time averaged diffusion coefficient

$$
\bar{D}(t)=\frac{1}{t} \int_{0}^{t} d t^{\prime} D\left(t^{\prime}\right) .
$$

The conversion procedure from sputter time during serial sectioning in the SIMS apparatus to absolute depth coordinates, i.e. the depth calibration, determines the accuracy of the diffusion coefficients. ${ }^{22}$ This depth calibration was performed with a Dektak 3030 (Veeco Instruments Inc.) profilometer after the sectioning process was finished. Due to the wavy surface structure of the specimens the calibration factor between depth and sputter time could be determined only with an uncertainty of about $\pm 15 \%$, which results in an uncertainty of the diffusion coefficients of typically $\pm 30 \%$.

Figures 2(a), (b) present typical penetration depth profiles of Fe, B, Al and Hf in V4. ${ }^{24,25)}$ The steep apparent increase of the concentration near the original position of the layer at $\Delta x=0$ is caused by an enhanced ionisation probability due to contaminations in the layer region. ${ }^{21,22)}$ This part of the curve was not considered for the evaluation of diffusion coefficients from the slopes which are marked by full lines.

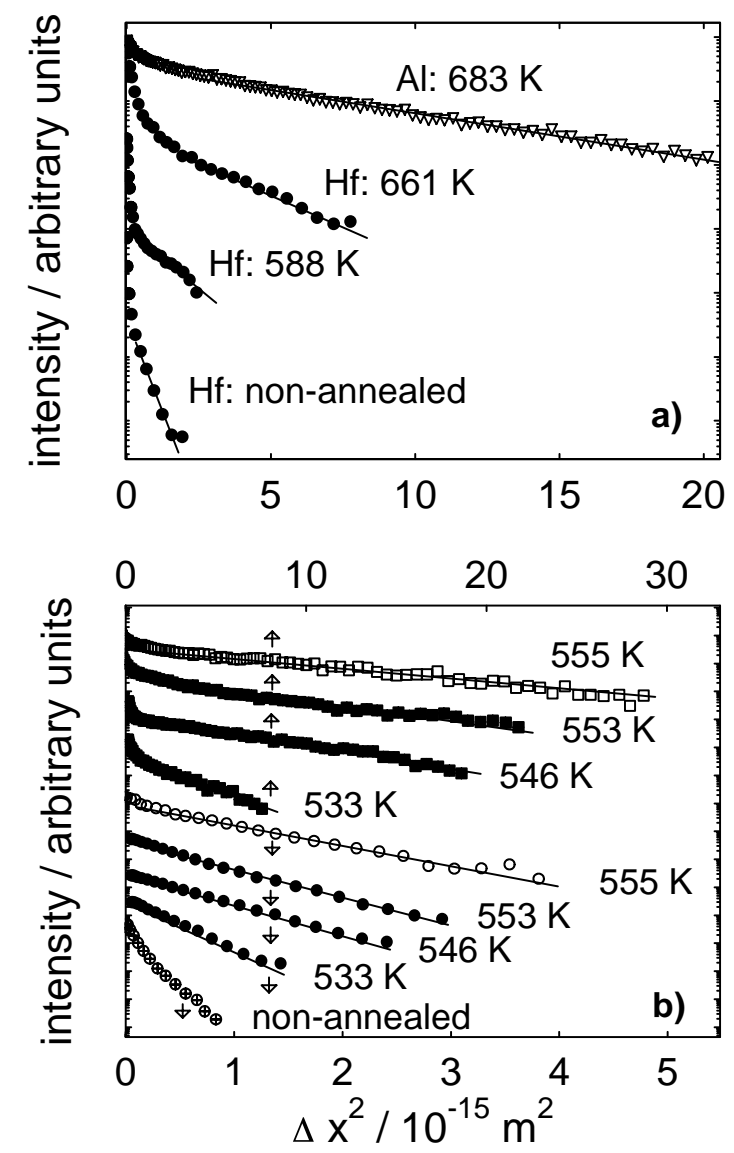

Fig. 2 Gaussian penetration plots of $\mathrm{Al}$ (open symbols) and Hf (closed symbols) diffusion in V4 bulk glass. Note the different scales for $\Delta x^{2}$.
The penetration depth of the impurities as measured in terms of $\sqrt{D t}$ is usually small and does not exceed about $200 \mathrm{~nm}^{18)}$ For the examples shown in Fig. 2(a) it ranges from about $5 \mathrm{~nm}(\mathrm{Hf}$ at $588 \mathrm{~K}$ ) to $50 \mathrm{~nm}(\mathrm{Al}$ at $683 \mathrm{~K}$ ). Since the annealing times must be kept short because of the potential instability of the glass small penetration depths have to be accepted which only slightly exceed the resolution limit of the experimental method of about $3.5 \mathrm{~nm}$. Small penetration depth are, on the other hand, of advantage because they largely reduce the possible influences of the primary crystals on the diffusivity. Taking a number density of primary crystals of about $2 \times 10^{16} \mathrm{~m}^{-318}$ ) the average jump distance of an atom in order to encounter one of these crystals is estimated to be larger than $10^{6} \mathrm{~nm}$. This is indeed many orders of magnitude larger than the largest penetration depths employed in the present diffusion experiments. It indicates a negligible influence of the primary crystals for these investigations.

\section{Results}

During isothermal treatment the glasses can change their structure towards the "metastable equilibrium" by relaxation, resulting in a time dependent diffusivity. ${ }^{21,26)}$ Since the reliable measurement of a diffusion coefficient requires always a certain minimum annealing time such measurements when performed during relaxation would yield a poorly defined average over various different states of the glass which is a result not very useful as a characteristic parameter for transport in the material. Hence, as a first step of a diffusion investigation on glasses it is always necessary to establish for any temperature an appropriate time range in which measurements can be made without significant structural changes occurring during the diffusion anneal. This situation is achieved either for measurements performed on well relaxed glasses which have already aquired their "metastable equilibrium", or for situations when the necessary diffusion time is small compared to the inherent relaxation time of the material. In the following we will characterize a relaxation towards the "metastable equilibrium" as being irreversible, if the relaxation effect cannot be recovered by annealing the material at a different temperature, as is true for instance with the annealing of quenched-in "free volume" in melt-spun glasses. ${ }^{21,26)}$

The structure of the supercooled liquid in "metastable equilibrium" is very likely temperature dependent. In the following we will characterize a relaxation as being reversible, if the relaxation effect is caused by adjustment of the structure belonging to a "metastable equilibrium" at one temperature to that at another temperature. Since the diffusion coefficients are affected by the glass structure we expect that the measured diffusion parameters, activation enthalpy $Q$ and prefactor $D_{0}$, are effective ones, reflecting both the temperature dependence of the structural state as well as that of the diffusivity.

In the next two sections we present measurements of the time and temperature dependent diffusion coefficients of different impurities in the four bulk glasses V1, D1, D2, and V4 which were processed partly in different ways. The results include measurements on samples containing a small amount of crystalline phase. 
Table 1 Time dependence of $\mathrm{B}, \mathrm{Fe}$, and $\mathrm{Al}$ diffusion coefficients $D$ and square of penetration depths $D t$ in $\mathrm{V} 1$.

\begin{tabular}{cccccccccc}
\hline $\begin{array}{c}\text { Diffusion time } \\
(\mathrm{ks})\end{array}$ & $\begin{array}{c}\text { Temperature } \\
(\mathrm{K})\end{array}$ & $\begin{array}{c}D t(\mathrm{~B}) \\
\left(\mathrm{nm}^{2}\right)\end{array}$ & $\begin{array}{c}D(\mathrm{~B}) \\
\left(10^{-19} \mathrm{~m}^{2} \mathrm{~s}^{-1}\right)\end{array}$ & $\begin{array}{c}D t(\mathrm{Fe}) \\
\left(\mathrm{nm}^{2}\right)\end{array}$ & $\begin{array}{c}D(\mathrm{Fe}) \\
\left(10^{-19} \mathrm{~m}^{2} \mathrm{~s}^{-1}\right)\end{array}$ & $\begin{array}{c}\text { Diffusion time } \\
(\mathrm{ks})\end{array}$ & $\begin{array}{c}\text { Temperature } \\
(\mathrm{K})\end{array}$ & $\begin{array}{c}D t(\mathrm{Al}) \\
\left(\mathrm{nm}^{2}\right)\end{array}$ & $\begin{array}{c}D(\mathrm{Al}) \\
\left(10^{-22} \mathrm{~m}^{2} \mathrm{~s}^{-1}\right)\end{array}$ \\
\hline 2.68 & 643 & 1560 & 5.82 & 270 & 1.01 & 6.9 & 624 & 12.75 & 18.5 \\
4.9 & 643 & 1792 & 3.66 & 392 & 0.8 & 18.42 & 624 & 18.17 & 9.86 \\
10.3 & 643 & 3019 & 2.93 & 579 & 0.56 & 28.62 & 624 & 28.15 & 9.84 \\
21.1 & 643 & 5531 & 2.62 & 1034 & 0.49 & 58.44 & 624 & 40.15 & 6.87 \\
53.2 & 643 & 20839 & 3.92 & 1733 & 0.33 & 110.1 & 624 & 44.4 & 4.03 \\
107.32 & 643 & 25095 & 2.34 & 1675 & 0.16 & 230.4 & 624 & 46.95 & 2.04 \\
0.36 & 643 & 287 & 7.97 & 37 & 1.03 & 368.82 & 624 & 42.6 & 1.16 \\
0.72 & 643 & 552 & 7.67 & 93 & 1.29 & 368.82 & 624 & 42.6 & 1.16 \\
1.44 & 643 & 1024 & 7.11 & 186 & 1.29 & 749.22 & 624 & 48.9 & 0.65 \\
2.7 & 643 & 1719 & 6.37 & 293 & 1.09 & 1302.48 & 624 & 29.99 & 0.23 \\
\hline
\end{tabular}

Table 2 Time dependence of B, Fe, and Al diffusion coefficients $D$ and square of penetration depths $D t$ in V4.

\begin{tabular}{|c|c|c|c|c|c|c|c|c|c|}
\hline $\begin{array}{l}\text { Diffusion } \\
\text { time }(\mathrm{ks})\end{array}$ & $\begin{array}{c}\text { Temperature } \\
\text { (K) }\end{array}$ & $\begin{array}{c}D t(\mathrm{~B}) \\
\left(10^{3} \mathrm{~nm}^{2}\right)\end{array}$ & $\begin{array}{c}D(\mathrm{~B}) \\
\left(10^{-19} \mathrm{~m}^{2} \mathrm{~s}^{-1}\right)\end{array}$ & $\begin{array}{c}D t(\mathrm{Fe}) \\
\left(10^{3} \mathrm{~nm}^{2}\right)\end{array}$ & $\begin{array}{c}D(\mathrm{Fe}) \\
\left(10^{-19} \mathrm{~m}^{2} \mathrm{~s}^{-1}\right)\end{array}$ & $\begin{array}{l}\text { Diffusion } \\
\text { time }(\mathrm{ks})\end{array}$ & $\begin{array}{c}\text { Temperature } \\
(\mathrm{K})\end{array}$ & $\begin{array}{c}D t(\mathrm{Al}) \\
\left(\mathrm{nm}^{2}\right)\end{array}$ & $\begin{array}{c}D(\mathrm{Al}) \\
\left(10^{-21} \mathrm{~m}^{2} \mathrm{~s}^{-1}\right)\end{array}$ \\
\hline 2.68 & 643 & 4.51 & 16.6 & 1.45 & 5.21 & 5.34 & 625 & 20 & 3.65 \\
\hline 20.8 & 643 & 33.88 & 16.3 & 11.05 & 5.29 & 25.74 & 625 & 118 & 4.58 \\
\hline \multirow[t]{2}{*}{64.3} & 643 & 88.93 & 13.8 & 22.98 & 3.57 & 79.26 & 625 & 327 & 4.12 \\
\hline & & & & & & 228.6 & 625 & 800 & 3.5 \\
\hline
\end{tabular}

\subsection{Time dependence of diffusion}

Indications for irreversible structural changes during a few hour's annealing of the V1 glass at temperatures above about $600 \mathrm{~K}$ were already deduced from small angle neutron scattering (SANS) results. ${ }^{8-10)}$ These were interpreted as isothermal decomposition of the glass into two phases. In Table 1 we present diffusion coefficients of $\mathrm{Al}, \mathrm{Fe}$, and $\mathrm{B}$ in this glass obtained at $624 \mathrm{~K}$ and $643 \mathrm{~K}$ using different diffusion times. The diffusion coefficients were derived according to eq. (3) as averages over the annealing time $t$, which is also given in the table. These data show a significant decrease of the Al, Fe and $\mathrm{B}$ diffusion coefficients at diffusion times of more than one hour. This time scale is compatible with the time scales derived from the isothermal structural changes of the same glass observed by SANS. ${ }^{8}{ }^{15)}$ The behavior of the V1 glass is in contrast to time averaged diffusion coefficients for the same impurities obtained in the V4 glass. These are summarized in Table 2. They show no significant time dependence during the annealing times used here, in accordance with recent SANS investigations which did not show decomposition in the V4 glass. ${ }^{11)}$ The data for the two glasses are compared in Fig. 3. The time dependence of the impurity diffusion coefficients in the investigated time-temperature range is characteristic for each glass indicating that it is indeed possible to perform time independent diffusion measurements even in those glasses which undergo irreversible relaxation.

Although the V4 glass is structurally stable at temperatures between about $620 \mathrm{~K}$ and $640 \mathrm{~K}$ for several hours (see Fig. 3) long term reversible structure changes are observed by their effect on the diffusivity at temperatures below about $600 \mathrm{~K}$. Table 3 summarizes the B and Fe diffusion coefficients obtained at $553 \mathrm{~K}$ on the $\mathrm{V} 4$ glass which was long time preannealed (relaxed). Both diffusion coefficients decrease by a factor of about three when the glass is pre-annealed at $553 \mathrm{~K}$

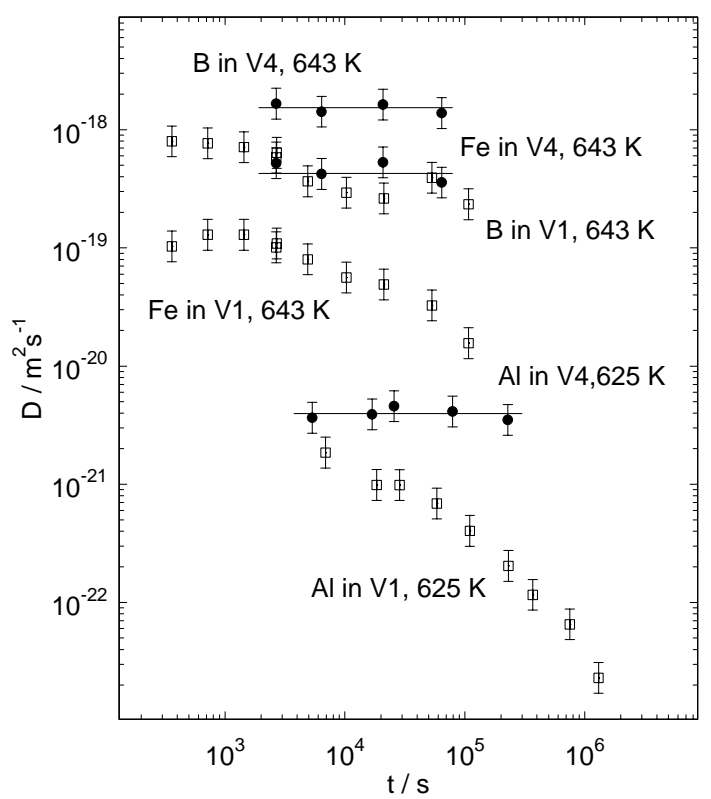

Fig. 3 Time dependence of the $\mathrm{Al}, \mathrm{Fe}$ and $\mathrm{B}$ diffusion coefficients in the V1 bulk glass (open symbols) and in the V4 bulk glass (closed symbols). The diffusion coefficients were derived according to eq. (3) of the text as averages over the annealing time t, details are given in Tables 1 and 2 .

for $1.6 \times 10^{7} \mathrm{~s}$ before the diffusion measurement, and the values of the as-cast glass are recovered when this relaxed material is annealed again for only $8.7 \times 10^{4} \mathrm{~s}$ at the higher temperature of $606 \mathrm{~K}$. This reversible structural relaxation was verified by DSC. ${ }^{27)}$ Figure 4 shows a series of DSC scans around the calorimetric glass transition at about $603 \mathrm{~K}$ which demonstrate reversible enthalpy recovery of the glass first relaxed at $553 \mathrm{~K}$ for 6 months and then annealed again at $606 \mathrm{~K}$ for one day. The total enthalpy gain of the underlying structural 

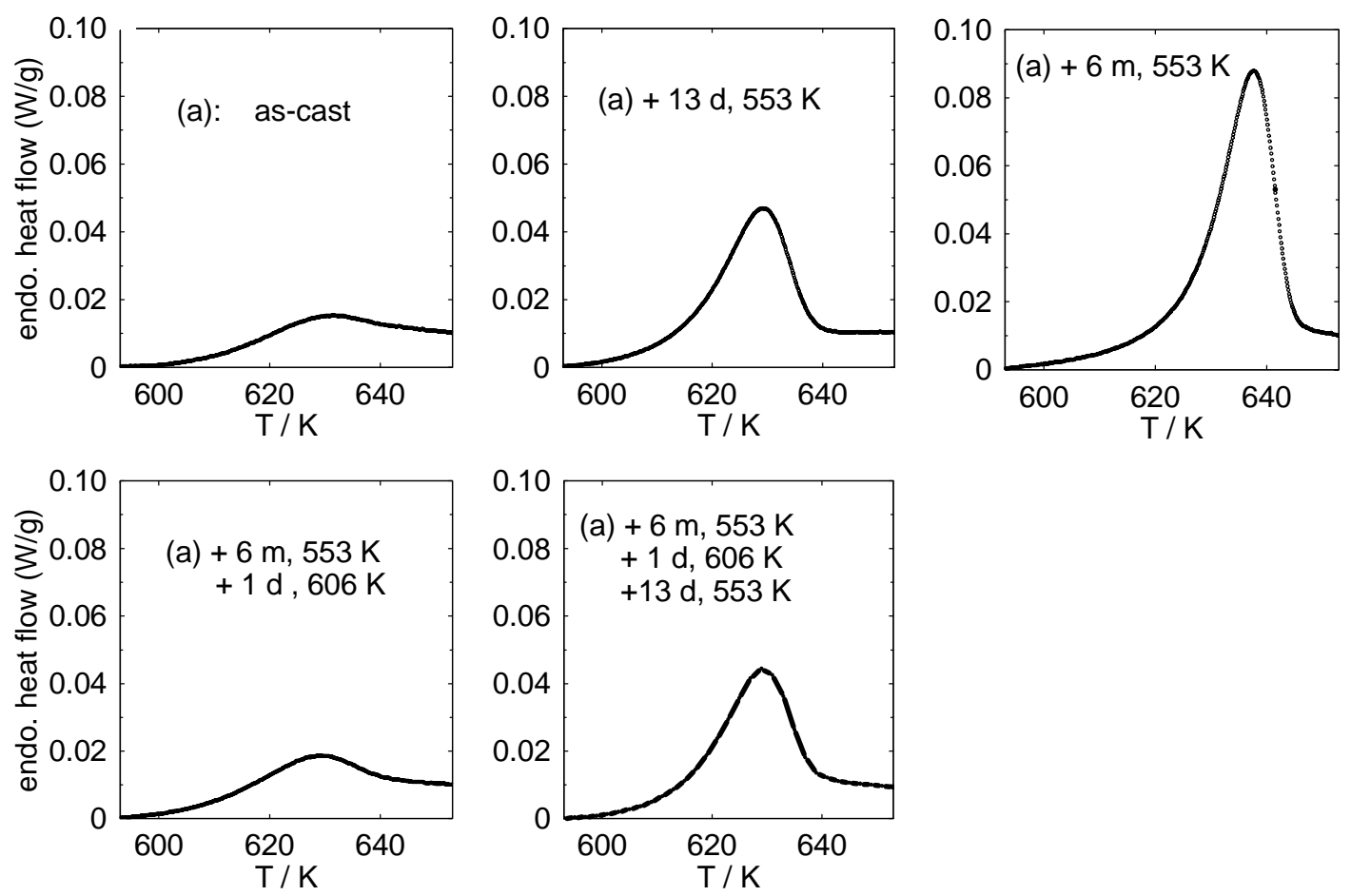

Fig. 4 Differential scanning calorimetric (DSC) plots of a V4 bulk glass sample which has been successively heat treated at different temperatures for different times as indicated in the figures. The heating rate was $0.067 \mathrm{~K} / \mathrm{s}$.

Table 3 Long time relaxation of B and Fe diffusion coefficients in V4. All diffusion coefficients were measured at $553 \mathrm{~K}$ with a diffusion time of $1.12 \times 10^{6} \mathrm{~s}$.

\begin{tabular}{ccc}
\hline Annealing procedure & $D(\mathrm{~B})\left(\mathrm{m}^{2} \mathrm{~s}^{-1}\right)$ & $D(\mathrm{Fe})\left(\mathrm{m}^{2} \mathrm{~s}^{-1}\right)$ \\
\hline Non-annealed (as-cast) & $1.75 \times 10^{-21}$ & $1.23 \times 10^{-22}$ \\
\hline As-cast +6 months at $553 \mathrm{~K}$ & $6.31 \times 10^{-22}$ & $3.6 \times 10^{-23}$ \\
\hline As-cast $+6 \mathrm{~m} / 553 \mathrm{~K}+1$ day at $606 \mathrm{~K}$ & $1.68 \times 10^{-21}$ & $1.01 \times 10^{-22}$ \\
\hline
\end{tabular}

changes was very small, only about $0.01 \mathrm{eV} / \mathrm{at}$, the relaxation time was about $10^{6} \mathrm{~s}$.

\subsection{Temperature dependence of diffusion}

The temperature dependence of B and Fe diffusion coefficients in the V1 glass was measured for the as-cast state, i.e. the diffusion times were short enough to avoid decomposition at high temperatures and long term relaxation at lower temperatures. Table 4 shows a compilation of these data. The corresponding data for the D1 and D2 glasses are given in Tables 5 and 6, respectively. A comparison of all these data is presented as Arrhenius plot in Fig. 5. It shows that the temperature dependences of B and Fe diffusion coefficients in these three glasses is very similar, respectively.

For a single thermally activated process the diffusion coefficients $D$ should follow a linear Arrhenius behavior, i.e. we expect that the relation $D=D_{0} \exp \left(-Q / k_{\mathrm{B}} T\right)$ is valid, with $D_{0}$ the pre-factor, $Q$ the activation enthalpy, $k_{\mathrm{B}}$ the Boltzmann constant and $T$ the temperature. Figure 5 shows, however, a non-linear Arrhenius behavior with different activation enthalpies at high $(T>600 \mathrm{~K})$ and low $(T<580 \mathrm{~K})$ temperatures, i.e. above and below the calorimetric glass transition. Activaton enthalpies $Q$ and pre-factors $D_{0}$ of the dif-
Table 4 Temperature dependence of B and Fe diffusion coefficients $D$ in V1.

\begin{tabular}{cccc}
\hline $\begin{array}{c}\text { Temperature } \\
(\mathrm{K})\end{array}$ & $\begin{array}{c}\text { Annealing time } \\
(\mathrm{ks})\end{array}$ & $\begin{array}{c}D(\mathrm{~B}) \\
\left(10^{-20} \mathrm{~m}^{2} \mathrm{~s}^{-1}\right)\end{array}$ & $\begin{array}{c}D(\mathrm{Fe}) \\
\left(10^{-21} \mathrm{~m}^{2} \mathrm{~s}^{-1}\right)\end{array}$ \\
\hline 513 & 10260.0 & 0.00331 & 0.00199 \\
533 & 3081.6 & 0.0217 & 0.0143 \\
554 & 264.4 & 0.0711 & 0.0492 \\
573 & 85.9 & 0.283 & 0.198 \\
593 & 172.3 & 0.18 & 0.654 \\
611 & 21.1 & 4.38 & 5.44 \\
628 & 53.5 & 12.2 & 18.8 \\
643 & 2.1 & 75.8 & 120.0 \\
658 & 1.44 & 237.0 & 621.0 \\
\hline
\end{tabular}

fusion coefficients derived in the different temperature ranges are compiled in Table 7.

The temperature dependence of $\mathrm{B}, \mathrm{Fe}, \mathrm{Co}, \mathrm{Al}$, and $\mathrm{Hf}$ diffusion in the as-cast V4 glass was measured between $513 \mathrm{~K}$ and $673 \mathrm{~K}$. The results are summarized in Table 8 and presented in the form of Arrhenius plots in Fig. 6. For the B, Fe, and Co diffusion these also indicate a non-linear Arrhenius behavior with significantly different activation enthalpies at high $(T>580 \mathrm{~K})$ and at low $(T<580 \mathrm{~K})$ temperatures. The $\mathrm{Al}$ and $\mathrm{Hf}$ diffusion coefficients showed a linear Arrhenius behavior, however, they were measured only down to $588 \mathrm{~K}$. The activation enthalpies $Q$ and pre-factors $D_{0}$ for impurity diffusion in V4 are collected in Table 7.

As has been shown above long term annealing of V4 at $553 \mathrm{~K}$ reduces the $\mathrm{B}$ and $\mathrm{Fe}$ diffusion coefficients by a factor of about three due to reversible structural relaxation. The temperature dependence of the diffusion coefficients of this long term relaxed glass was measured between $533 \mathrm{~K}$ and $638 \mathrm{~K}$. 
Table 5 Temperature dependence of B and Fe diffusion coefficients $D$ in D1.

\begin{tabular}{cccc}
\hline $\begin{array}{c}\text { Temperature } \\
(\mathrm{K})\end{array}$ & $\begin{array}{c}\text { Diffusion time } \\
(\mathrm{ks})\end{array}$ & $\begin{array}{c}D(\mathrm{~B}) \\
\left(10^{-20} \mathrm{~m}^{2} \mathrm{~s}^{-1}\right)\end{array}$ & $\begin{array}{c}D(\mathrm{Fe}) \\
\left(10^{-21} \mathrm{~m}^{2} \mathrm{~s}^{-1}\right)\end{array}$ \\
\hline 513 & 8314.8 & 0.0014 & 0.0021 \\
533 & 3883.0 & 0.0061 & \\
551 & 1631.6 & 0.0456 & 0.018 \\
555 & 348.2 & 0.0671 & 0.0233 \\
573 & 516.2 & 0.183 & 0.246 \\
585 & 88.4 & 0.573 & 1.18 \\
612 & 86.4 & 3.38 & 5.04 \\
628 & 53.5 & 10.7 & 27.0 \\
642 & 57.0 & 40.5 & 62.8 \\
651 & 2.1 & 69.4 & 237 \\
657 & 1.2 & 69.2 & 322 \\
\hline
\end{tabular}

Table 6 Temperature dependence of B and Fe diffusion coefficients $D$ in D2.

\begin{tabular}{cccc}
\hline $\begin{array}{c}\text { Temperature } \\
(\mathrm{K})\end{array}$ & $\begin{array}{c}\text { Diffusion time } \\
(\mathrm{ks})\end{array}$ & $\begin{array}{c}D(\mathrm{~B}) \\
\left(10^{-20} \mathrm{~m}^{2} \mathrm{~s}^{-1}\right)\end{array}$ & $\begin{array}{c}D(\mathrm{Fe}) \\
\left(10^{-21} \mathrm{~m}^{2} \mathrm{~s}^{-1}\right)\end{array}$ \\
\hline 513 & 8314.8 & 0.00445 & 0.00397 \\
533 & 3883.0 & 0.0202 & 0.0151 \\
551 & 1631.6 & 0.0986 & 0.0293 \\
555 & 348.2 & 0.149 & 0.353 \\
573 & 516.2 & 0.366 & 0.423 \\
585 & 88.4 & 0.901 & 0.635 \\
612 & 86.4 & 3.79 & 2.29 \\
628 & 53.5 & 11.9 & 7.77 \\
642 & 57.0 & 44.5 & 80.7 \\
653 & 2.1 & 71.1 & 78.0 \\
657 & 1.2 & 164 & 212 \\
\hline
\end{tabular}

The data are collected in Table 9 and plotted in Fig. 7. Comparison with the diffusion coefficients of the as-cast V4 glass indicates that after long term annealing the diffusion coefficients of $\mathrm{B}$ and $\mathrm{Fe}$ show linear Arrhenius plots in the entire temperature range with activation enthalpies corresponding to those of the high temperature branch. ${ }^{25}$ )

Splat-cooling with quenching rates comparable to those of melt-spun glasses should produce an enhanced fraction of "free volume"28,29) which can give rise to an increased diffusivity. ${ }^{21,26)}$ The B and Fe diffusion coefficients obtained in the splat-cooled V4 glass are collected in Table 10 and compared with those obtained for the as-cast bulk glass in Fig. 8. The two data sets agree in the entire temperature range within the experimental uncertainties indicating a small if any effect of fast cooling rates on the diffusivity in V4.

Some samples of the V4 glass were annealed at $643 \mathrm{~K}$ for $6 \mathrm{~h}$ and $9 \mathrm{~h}$ in order to completely relax the material and partly crystallize it. While the XRD pattern of the material after $6 \mathrm{~h}$ annealing was indistinguishable from that of the as-cast glass Bragg peaks were observed after $9 \mathrm{~h}$ annealing which indicated the presence of less than $10 \%$ of a quasicrystalline icosahedral phase. ${ }^{30,31)}$ The $\mathrm{B}$ and Fe diffusion coefficients obtained on this material are summarized in Table 11 and compared with the results on the as-cast V4 glass in Fig. 9. We find agreement within the experimental uncertainties between the two data sets. This indicates a negligible effect

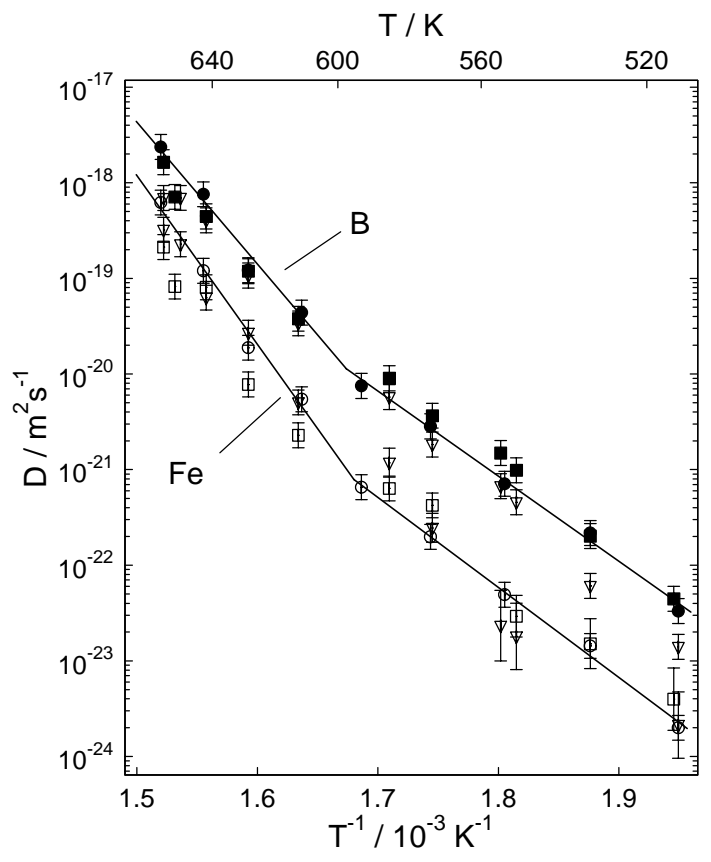

Fig. 5 Arrhenius plot of B (closed symbols) and Fe (open symbols) diffusion coefficients in the three bulk glasses D1 (squares), D2 (triangles) and V1 (circles). Details are given in the text and in Tables 4, 5 and 6.

Table 7 Activation energy $Q$ and pre-factor $D_{0}$ of $\mathrm{B}, \mathrm{Fe}, \mathrm{Co}, \mathrm{Al}$, and $\mathrm{Hf}$ diffusion coefficients in V1, V4, D1, D2. Typical random errors are $0.2 \mathrm{eV}$ for $Q$ and 1,5 for $\log D_{0}$.

\begin{tabular}{|c|c|c|c|c|c|}
\hline \multirow[t]{2}{*}{ Glass } & \multirow[t]{2}{*}{ Tracer } & $D_{0}\left(\mathrm{~m}^{2} \mathrm{~s}^{-1}\right)$ & $Q(\mathrm{eV})$ & $D_{0}\left(\mathrm{~m}^{2} \mathrm{~s}^{-1}\right)$ & $Q(\mathrm{eV})$ \\
\hline & & \multicolumn{2}{|c|}{ Low temperature regime } & \multicolumn{2}{|c|}{ High temperature regime } \\
\hline \multirow[t]{2}{*}{ V1 } & $\mathrm{Fe}$ & $1.08 \times 10^{-5}$ & 1.91 & $2.26 \times 10^{8}$ & 3.48 \\
\hline & B & $1.73 \times 10^{-5}$ & 1.80 & $1.22 \times 10^{5}$ & 2.97 \\
\hline \multirow[t]{5}{*}{ V4 } & $\mathrm{Fe}$ & $1.98 \times 10^{-3}$ & 2.11 & $2.76 \times 10^{6}$ & 3.16 \\
\hline & B & $1.89 \times 10^{-4}$ & 1.87 & $2.84 \times 10^{2}$ & 2.59 \\
\hline & $\mathrm{Co}$ & $7.3 \times 10^{-4}$ & 2.01 & $3.05 \times 10^{5}$ & 3.00 \\
\hline & $\mathrm{Al}$ & & & $3.19 \times 10^{12}$ & 4.09 \\
\hline & Hf & & & $3.76 \times 10^{10}$ & 3.76 \\
\hline \multirow[t]{2}{*}{ D1 } & $\mathrm{Fe}$ & $2.05 \times 10^{-2}$ & 2.27 & $7.24 \times 10^{5}$ & 3.17 \\
\hline & B & $3.14 \times 10^{-2}$ & 2.18 & $1.24 \times 10^{1}$ & 2.50 \\
\hline \multirow[t]{2}{*}{ D2 } & $\mathrm{Fe}$ & $4.80 \times 10^{-6}$ & 1.85 & $4.58 \times 10^{7}$ & 3.44 \\
\hline & B & $1.19 \times 10^{-4}$ & 1.87 & $2.11 \times 10^{3}$ & 2.77 \\
\hline
\end{tabular}

of the quenched-in "free volume" on diffusivity in this bulk glass. It moreover shows that small amounts of crystals and the accompanying local decomposition have likewise no detectable effect on the diffusivity in V4.

\section{Discussion}

Upon annealing above about $600 \mathrm{~K}$ the V1 bulk glass decomposes into a two-phase structure. ${ }^{8-10)}$ Of these phases one is rich in $\mathrm{Be}$ and $\mathrm{Zr}$ and poor in $\mathrm{Ti}$ and $\mathrm{Cu}$, the other rich in $\mathrm{Ti}$ and $\mathrm{Cu}$ and poor in $\mathrm{Be}$ and $\mathrm{Zr} .{ }^{13,31)}$ Furthermore $\mathrm{ZrTi}$ enriched regions have been found in annealed V1. ${ }^{33)}$ Volume fractions of more than $10 \%$ of nanoparticles in the decomposed matrix 


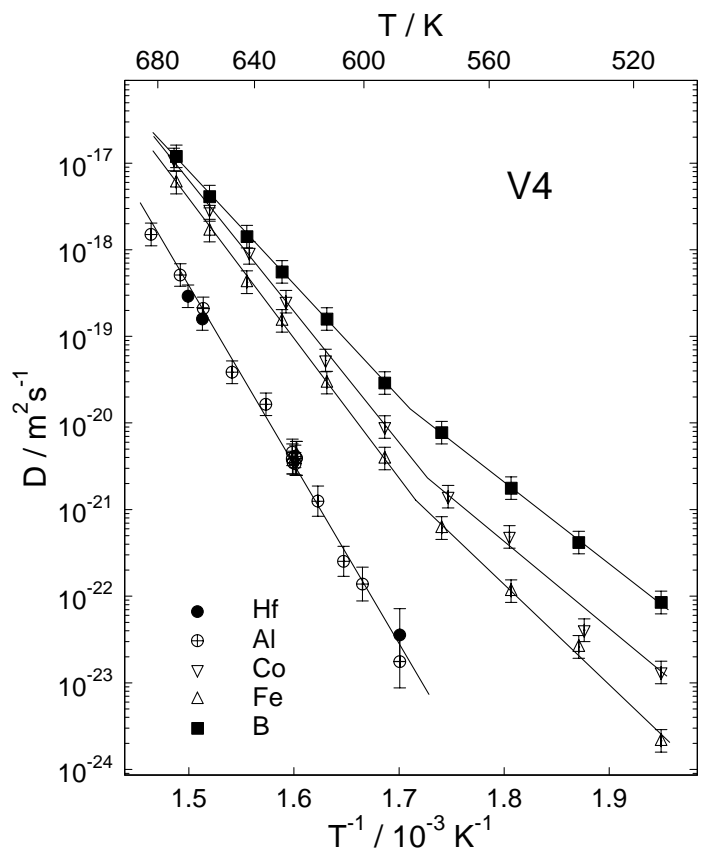

Fig. 6 Arrhenius plot of $\mathrm{B}$ (full squares), $\mathrm{Fe}$ (up-triangles), Co (down-triangles), $\mathrm{Al}$ (crossed circles) and $\mathrm{Hf}$ (full circles) diffusion coefficients in the V4 bulk glass. Lines are least-mean-squares fits to all data points $(\mathrm{Al})$, or separately to four data points $(\mathrm{B}, \mathrm{Fe}, \mathrm{Co})$ at lower temperatures $(<580 \mathrm{~K})$ and six data points at higher temperatures $(>580 \mathrm{~K})$.

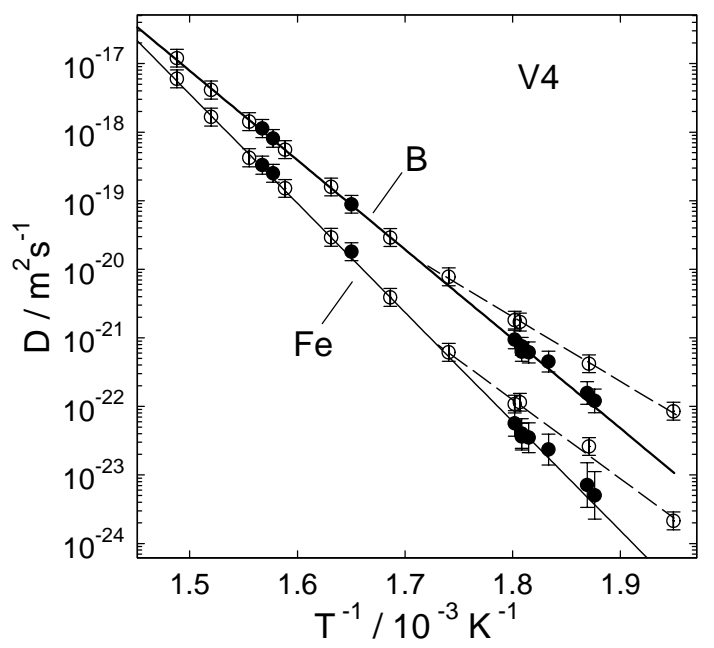

Fig. 7 Arrhenius plot of B and Fe diffusion coefficients (full symbols) in long term annealed $\left(1.58 \times 10^{7} \mathrm{~s}, 553 \mathrm{~K}\right) \mathrm{V} 4$ bulk glass. The full lines are least-mean-squares fits to the data. Open symbols and dashed lines indicate the behavior of the as-cast V4 bulk glass as given in Fig. 6.

have been derived from SANS results. ${ }^{34)}$ In general, the rate of decomposition becomes smaller with time and a limiting degree of decomposition is found. ${ }^{9}{ }^{15,35)}$ At higher temperatures the decomposition is faster and slows down at a higher level of decomposition. ${ }^{9)}$ Having reached its final degree of decomposition at one temperature, further decomposition occurs when the sample is annealed at a higher temperature than before. ${ }^{34)}$

A decrease of the $\mathrm{B}$ and Fe diffusion coefficients in the V1 glass with increasing diffusion time at $643 \mathrm{~K}$ is demonstrated in Fig. 3. Similar results were obtained in this glass at $623 \mathrm{~K}^{15)}$ The D1 and D2 bulk glasses are also unstable quite
Table 8 Temperature dependence of $\mathrm{B}, \mathrm{Fe}, \mathrm{Co}, \mathrm{Al}$, and $\mathrm{Hf}$ diffusion coefficients $D$ in V4

\begin{tabular}{|c|c|c|c|}
\hline $\begin{array}{c}\text { Temperature } \\
\text { (K) }\end{array}$ & $\begin{array}{l}\text { Diffusion time } \\
(\mathrm{ks})\end{array}$ & $\begin{array}{c}D(\mathrm{~B}) \\
\left(10^{-20} \mathrm{~m}^{2} \mathrm{~s}^{-1}\right)\end{array}$ & $\begin{array}{c}D(\mathrm{Fe}) \\
\left(10^{-21} \mathrm{~m}^{2} \mathrm{~s}^{-1}\right)\end{array}$ \\
\hline 513 & 10260.0 & 0.00849 & 0.00214 \\
\hline 534 & 923.2 & 0.0418 & 0.026 \\
\hline 554 & 348.7 & 0.177 & 0.115 \\
\hline 574 & 172.9 & 0.777 & 0.613 \\
\hline 593 & 83.5 & 2.90 & 3.88 \\
\hline 613 & 51.7 & 15.9 & 29.2 \\
\hline 630 & 10.0 & 55.5 & 151 \\
\hline 643 & 6.4 & 142 & 422 \\
\hline 658 & 3.1 & 411 & 1660 \\
\hline 672 & 3.58 & 1200 & 5980 \\
\hline $\begin{array}{c}\text { Temperature } \\
\text { (K) }\end{array}$ & \multicolumn{2}{|c|}{$\begin{array}{l}\text { Diffusion time } \\
(\mathrm{ks})\end{array}$} & $\begin{array}{c}D(\mathrm{Co}) \\
\left(10^{-21} \mathrm{~m}^{2} \mathrm{~s}^{-1}\right)\end{array}$ \\
\hline 513 & \multicolumn{2}{|c|}{9219.0} & 0.0132 \\
\hline 533 & \multicolumn{2}{|c|}{3081.1} & 0.0405 \\
\hline 554 & \multicolumn{2}{|c|}{665.5} & 0.486 \\
\hline 573 & \multicolumn{2}{|c|}{349.9} & 1.41 \\
\hline 593 & \multicolumn{2}{|c|}{172.9} & 8.98 \\
\hline 614 & \multicolumn{2}{|c|}{52.9} & 52.7 \\
\hline 628 & \multicolumn{2}{|c|}{11.2} & 251 \\
\hline 642 & \multicolumn{2}{|c|}{3.1} & 920 \\
\hline 658 & \multicolumn{2}{|c|}{4.3} & 2880 \\
\hline 673 & \multicolumn{2}{|c|}{2.2} & 11000 \\
\hline $\begin{array}{c}\text { Temperature } \\
\text { (K) }\end{array}$ & \multicolumn{2}{|c|}{$\begin{array}{l}\text { Diffusion time } \\
\qquad(\mathrm{ks})\end{array}$} & $\begin{array}{c}D(\mathrm{Al}) \\
\left(10^{-21} \mathrm{~m}^{2} \mathrm{~s}^{-1}\right)\end{array}$ \\
\hline 588 & \multicolumn{2}{|c|}{1394.7} & 0.0176 \\
\hline 600 & \multicolumn{2}{|c|}{397.5} & 0.138 \\
\hline 607 & \multicolumn{2}{|c|}{346.62} & 0.253 \\
\hline 616 & \multicolumn{2}{|c|}{74.4} & 1.25 \\
\hline 624 & \multicolumn{2}{|c|}{16.86} & 3.90 \\
\hline 624 & \multicolumn{2}{|c|}{5.34} & 3.92 \\
\hline 624 & \multicolumn{2}{|c|}{79.26} & 4.12 \\
\hline 625 & \multicolumn{2}{|c|}{228.6} & 3.50 \\
\hline 625 & \multicolumn{2}{|c|}{25.74} & 4.02 \\
\hline 636 & \multicolumn{2}{|c|}{12.3} & 16.4 \\
\hline 649 & \multicolumn{2}{|c|}{1.5} & 38.5 \\
\hline 661 & \multicolumn{2}{|c|}{1.6} & 210 \\
\hline 670 & \multicolumn{2}{|c|}{1.57} & 510 \\
\hline 683 & \multicolumn{2}{|c|}{0.95} & 1500 \\
\hline $\begin{array}{c}\text { Temperature } \\
(\mathrm{K})\end{array}$ & \multicolumn{2}{|c|}{$\begin{array}{l}\text { Diffusion time } \\
(\mathrm{ks})\end{array}$} & $\begin{array}{c}D(\mathrm{Hf}) \\
\left(10^{-21} \mathrm{~m}^{2} \mathrm{~s}^{-1}\right)\end{array}$ \\
\hline 585 & & & 0.0357 \\
\hline 661 & & .5 & 159 \\
\hline 667 & & .2 & 291 \\
\hline
\end{tabular}

similar to the V1 glass. ${ }^{6)}$ This is to be expected since these two glasses do not represent true decomposition phases of V1 at a temperature of $643 \mathrm{~K}^{14)}$ The $\mathrm{B}$ and Fe diffusion coefficients obtained in the time independent range and shown in Fig. 5 were each found to be very similar for the V1, D1, and D2 glasses. Moreover, comparison with Fig. 6 shows that in the V4 glass the B and Fe diffusion coefficients are higher by only a factor of about three. These results indicate that the com- 
Table 9 Temperature dependence of B and Fe diffusion coefficients $D$ after pre-annealing for different times $t_{\mathrm{pa}}$ at $553 \mathrm{~K}$. The uncertainty of the diffusion coefficients is generally about $\pm 30 \%$, except for $D(\mathrm{Fe})$ measured at $535 \mathrm{~K}$ and $533 \mathrm{~K}$, where it amounts up to about $\pm 80 \%$.

\begin{tabular}{|c|c|c|c|c|}
\hline \multirow[t]{2}{*}{$t_{\mathrm{pa}}(\mathrm{s})$} & \multicolumn{2}{|c|}{ Diffused } & \multirow{2}{*}{$\begin{array}{c}D(\mathrm{~B}) \\
\left(\mathrm{m}^{2} \mathrm{~s}^{-1}\right)\end{array}$} & \multirow{2}{*}{$\begin{array}{c}D(\mathrm{Fe}) \\
\left(\mathrm{m}^{2} \mathrm{~s}^{-1}\right)\end{array}$} \\
\hline & $T / \mathrm{K}$ & $t / \mathrm{s}$ & & \\
\hline \multirow[t]{2}{*}{$1.12 \times 10^{6}$} & 551 & $1.73 \times 10^{6}$ & $6.1 \times 10^{-22}$ & $3.5 \times 10^{-23}$ \\
\hline & 555 & $1.22 \times 10^{6}$ & $9.5 \times 10^{-22}$ & $5.7 \times 10^{-23}$ \\
\hline $5.27 \times 10^{6}$ & 553 & $1.79 \times 10^{6}$ & $7.5 \times 10^{-22}$ & $4.0 \times 10^{-23}$ \\
\hline \multirow[t]{6}{*}{$1.58 \times 10^{7}$} & 533 & $1.79 \times 10^{6}$ & $1.2 \times 10^{-22}$ & $5.0 \times 10^{-24}$ \\
\hline & 546 & $1.73 \times 10^{6}$ & $4.5 \times 10^{-22}$ & $2.4 \times 10^{-23}$ \\
\hline & 553 & $1.79 \times 10^{6}$ & $6.3 \times 10^{-22}$ & $3.6 \times 10^{-23}$ \\
\hline & 606 & $8.67 \times 10^{4}$ & $8.9 \times 10^{-20}$ & $1.8 \times 10^{-20}$ \\
\hline & 634 & $5.20 \times 10^{3}$ & $8.1 \times 10^{-19}$ & $2.5 \times 10^{-19}$ \\
\hline & 638 & $6.90 \times 10^{3}$ & $1.1 \times 10^{-18}$ & $3.3 \times 10^{-19}$ \\
\hline $2.37 \times 10^{7}$ & 535 & $2.60 \times 10^{6}$ & $1.6 \times 10^{-22}$ & $7.1 \times 10^{-24}$ \\
\hline
\end{tabular}

Table 10 Temperature dependence of B and Fe diffusion coefficients $D$ in splat-cooled V4.

\begin{tabular}{cccc}
\hline $\begin{array}{c}\text { Temperature } \\
(\mathrm{K})\end{array}$ & $\begin{array}{c}\text { Diffusion time } \\
(\mathrm{ks})\end{array}$ & $\begin{array}{c}D(\mathrm{~B}) \\
\left(10^{-20} \mathrm{~m}^{2} \mathrm{~s}^{-1}\right)\end{array}$ & $\begin{array}{c}D(\mathrm{Fe}) \\
\left(10^{-21} \mathrm{~m}^{2} \mathrm{~s}^{-1}\right)\end{array}$ \\
\hline 554 & 1119.6 & 0.235 & 0.142 \\
576 & 86.4 & 0.802 & 1.33 \\
591 & 88.5 & 3.82 & 6.48 \\
623 & 75.2 & 35.7 & 106 \\
654 & 5.4 & 312 & 1250 \\
\hline
\end{tabular}

position of the glasses or of the decomposition phases cannot be responsible for the strong time dependence of the diffusivity during decomposition of the V1 glass. We believe that some not yet identified structural alterations which occur during decomposition cause the observed irreversible relaxation of the diffusivities. We note that a small fraction of crystals assumed to form polymorphously during decomposition ${ }^{8)}$ is most likely not the reason for time dependent diffusion coefficients, since we have found that partial crystallization has a negligible effect on diffusivity in the V4 glass.

Structural relaxation in rapidly quenched melt spun metallic glasses, e.g. in the metal-metalloid FeNiB glass, is usually accompanied by a volume density increase of the order of a few tenths of a percent. ${ }^{28,36)}$ This effect has been attributed to the elimination of excess of free volume retained from the fast quenching of the liquid state during the production process. It is proposed that during this irreversible relaxation units of free volume, so-called quasi-vacancies, anneal via thermally activated migration resulting in the observed decrease of the diffusion coefficients by more than one order of magnitude. ${ }^{21,26)}$

The B and Fe diffusion coefficients obtained for the splat cooled V4 glass fit well to those of the as-cast V4 glass (see Fig. 8) indicating a negligible influence of the cooling rate on the diffusivity. This is a result not to be expected. The positron life time and density measurements performed by Nagel et al. ${ }^{29)}$ showed that a considerable amount of excess volume which is of similar magnitude as that observed for an amorphous melt-spun FeSiB ribbon can be quenched-in in the

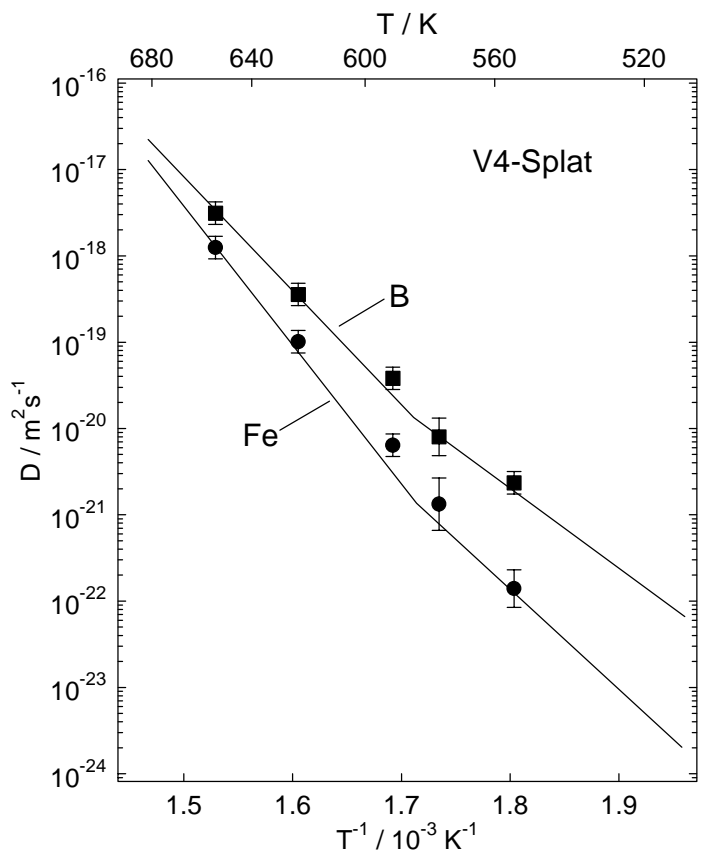

Fig. 8 Arrhenius plot of B and Fe diffusion coefficients in splat-cooled V4 glass. The lines indicate the behavior of the as-cast V4 bulk glass as given in Fig. 6.

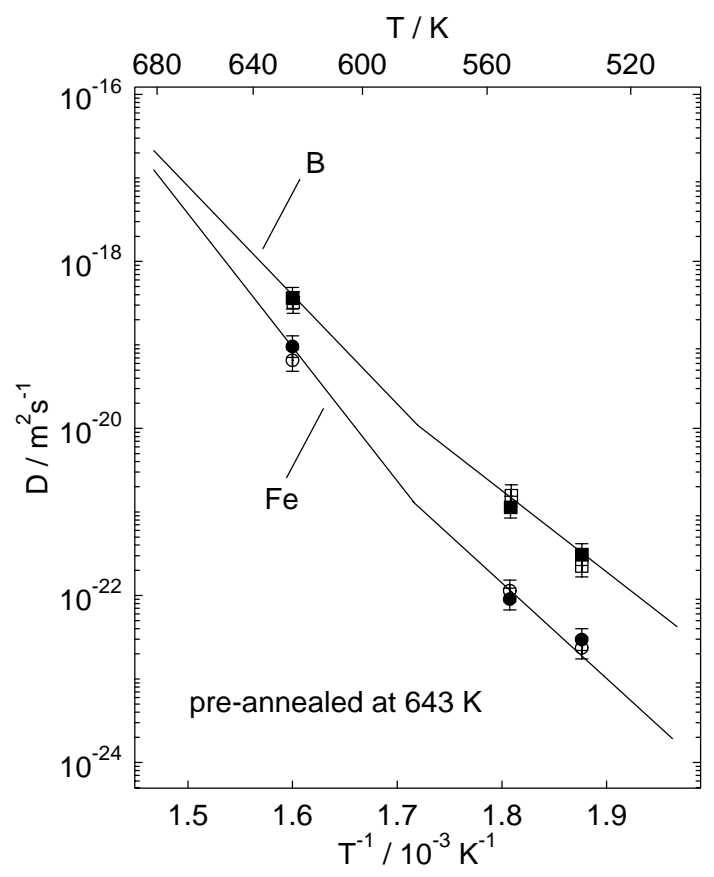

Fig. 9 Arrhenius plot of B and Fe diffusion coefficients in V4 bulk glass annealed at $643 \mathrm{~K}$ for $6 \mathrm{~h}$ (closed symbols) and $9 \mathrm{~h}$ (open symbols). The lines indicate the behavior of the as-cast V4 bulk glass as given in Fig. 6.

V4 metallic glass. After annealing the V4 glass at $643 \mathrm{~K}$ for $6 \mathrm{~h}$ this glass should contain a negligible amount of quenchedin free volume. This assumption should also hold for the partially crystallized state after annealing at $643 \mathrm{~K}$ for $9 \mathrm{~h}$ when the volume fraction of crystals was smaller than $10 \% .^{31)}$ The results shown in Fig. 9 indicate agreement between the B and Fe diffusion coefficients of the pre-annealed and partly crystallized V4 glass with the data of the as-cast glass over the entire temperature interval of the investigation, i.e. impurity 
Table 11 Temperature dependence of B and Fe diffusion coefficients $D$ in V4 pre-annealed at $643 \mathrm{~K}$.

\begin{tabular}{|c|c|c|c|c|}
\hline & $\begin{array}{c}\text { Temperature } \\
(\mathrm{K})\end{array}$ & $\begin{array}{l}\text { Diffusion time } \\
(\mathrm{ks})\end{array}$ & $\begin{array}{c}D(\mathrm{~B}) \\
\left(10^{-20} \mathrm{~m}^{2} \mathrm{~s}^{-1}\right)\end{array}$ & $\begin{array}{c}D(\mathrm{Fe}) \\
\left(10^{-21} \mathrm{~m}^{2} \mathrm{~s}^{-1}\right)\end{array}$ \\
\hline Pre-annealed for & 533 & 2476.8 & 0.0308 & 0.0296 \\
\hline \multirow[t]{2}{*}{$6 \mathrm{~h}$} & 553 & 119.6 & 0.114 & 0.0779 \\
\hline & 625 & 14.4 & 34.2 & 69.9 \\
\hline Pre-annealed for & 533 & 2476.8 & 0.0291 & 0.0235 \\
\hline \multirow[t]{2}{*}{$9 \mathrm{~h}$} & 553 & 119.6 & 0.118 & 0.0977 \\
\hline & 625 & 14.4 & 28.2 & 71.0 \\
\hline
\end{tabular}

diffusion in the V4 bulk glass seems to depend neither on the cooling rate with which the glass was produced nor on an annealing above the calorimetric glass transition. It can be concluded that the amount of excess free volume in the present experiments is of minor importance for the magnitude of the diffusion coefficients. If the total effect of free volume on the diffusion coefficients in V4 is of similar magnitude as that observed in melt-spun $\mathrm{Fe}_{40} \mathrm{Ni}_{40} \mathrm{~B}_{20}$ (in which it is about $5 \times 10^{-21} \mathrm{~m}^{2} / \mathrm{s}$ for the Fe diffusion coefficient at $615 \mathrm{~K}^{21,26)}$ ) then we expect that this effect is hidden in the experimental error bar of the diffusion coefficients (about $10^{-20} \mathrm{~m}^{2} / \mathrm{s}$ for $\mathrm{Fe}$ diffusion at $615 \mathrm{~K}$ ) in V4.

The striking feature of the diffusivities measured in the ascast bulk glasses is their non-linear Arrhenius behavior, which was described by different parameters in the high and low temperature range (see Figs. 5, 6, and Table 7). Moreover the magnitude of the diffusion parameters $Q$ and $D_{0}$ obtained in the high temperature range is noteworthy. These parameters are much higher than expected from diffusion in crystals. ${ }^{37)}$ The reason for this as well as for the specific correlation between $D_{0}$ and $Q$ found universally in glasses ${ }^{38)}$ are up to now unknown. A non-linear Arrhenius behavior of diffusion coefficients was also reported for three other members of the class of bulk glasses, $\mathrm{Zr}_{65} \mathrm{Cu}_{17.5} \mathrm{Ni}_{10} \mathrm{Al}_{7.5}$, ${ }^{39)} \mathrm{Zr}_{55} \mathrm{Cu}_{25} \mathrm{Ni}_{10} \mathrm{Al}_{10}$, ${ }^{40}$ ) and $\mathrm{Pd}_{40} \mathrm{Cu}_{30} \mathrm{Ni}_{10} \mathrm{P}_{20}{ }^{41,42)}$ indicating that such behavior is a general feature of these materials. With the results shown in Figs. 4 and 7 we answer the long standing question whether the different branches of temperature dependent diffusion coefficients are due to diffusion mechanisms which are different above and below the calorimetric glass transition. ${ }^{41,43,44)}$ Our results clearly indicate a reversible structural relaxation effect, i.e. the influence of the thermal history on the diffusion coefficients in the V4 bulk glass at and below $575 \mathrm{~K}$. This reversible relaxation leads to a reduction of the diffusion coefficients of about $50 \%$ at $553 \mathrm{~K}$ and of $70 \%$ to $80 \%$ at $535 \mathrm{~K}$ if the results of the as-cast material and those of the relaxed are compared (see Fig. 7). Above $575 \mathrm{~K}$ no effect of a pre-annealing at $553 \mathrm{~K}$ was observed because reversible relaxation at these temperatures is fast and the glass attains its metastable equilibrium in times which are short compared to usual experiment times. Quite similar results were recently obtained for Fe diffusion in the $\mathrm{Pd}_{40} \mathrm{Cu}_{30} \mathrm{Ni}_{10} \mathrm{P}_{20}$ bulk glass. ${ }^{42)}$

It is obvious from these results that even slow cooling rates as are applied during glass production (and leading to the "as-cast" glass) or furnace cooling of diffusion samples quench the glass structure at a temperature in the vicinity of the calorimetric glass transition. Since the B and Fe diffusion coefficients derived from the reversibly relaxed V4 fit to the high temperature $(>575 \mathrm{~K}$ ) data of the as-cast material our results support the interpretation that the non-linear Arrhenius behavior of the diffusion coefficients is caused by structural changes alone, i.e. by insufficient adjustment of the actual structure to that of the supercooled liquid state at low temperatures. ${ }^{39)}$ Hence the diffusion coefficients which are measured in the as-cast material at these temperatures reflect merely the transport properties of a configurational state representing the supercooled liquid structure frozen from a higher temperature. It is remarkable that the structural changes during the reversible relaxation are characterized by an enthalpy change of only $0.01 \mathrm{eV}^{27}$ ) while the difference of effective activation enthalpies of diffusion obtained from the high and low temperature branch of the Arrhenius plots is roughly $1 \mathrm{eV}$ (see Table 7). This large difference reflects the general observation that small changes of the glass structure by relaxation becoming visible e.g. in its radial distribution function, ${ }^{45)}$ can have a huge influence on the glass dynamics as is illustrated here by their effect on the diffusivity.

\section{Summary}

Bulk glasses of the ZrTiCuNiBe family are sufficiently stable above the calorimetric glass transition to allow measurements for extended time periods in this temperature range. Detailed investigations in a large temperature range around the calorimetric glass transition revealed a non-linear Arrhenius behavior of the diffusivity in these bulk glasses. At high temperatures the diffusivity is only weakly dependent on the composition of these glasses, and is practically not affected by the amount of quenched-in free volume or a small volume fraction of crystals. The diffusivity is, however, strongly affected by structural changes of the glass. These are either due to chemical decomposition of the glass which leads to an irreversible decrease of the diffusivities, or due to the reversible adjustment of the actual structure to its metastable equilibrium state. The reversible relaxation becomes detectable only at temperatures below the calorimetric glass transition. Our results indicate that the non-linear Arrhenius behavior of the diffusivity is caused by insufficient relaxation of the glass at the diffusion temperatures. The diffusion parameters $Q$ and $D_{0}$ found for the metastable equilibrium state of the glass at temperatures above the calorimetric glass transition are valid also below the glass transition if the 
glass is properly relaxed at these lower temperatures. These parameters are much larger than would be expected from diffusion in crystals. This points to their effective nature and is probably caused by a strong influence of the temperature dependent structure on the atomic transport mechanism.

\section{Acknowledgements}

We are grateful to Drs. Elisabeth Budke and Jörg Rüsing who were involved in an early stage of the here described work, and to Dr. C. Abromeit for critically reading the manuscript. Financial support of the DFG under project nos. Fr 223/10-1-4; Ma 1832/2-1-2 is acknowledged.

\section{REFERENCES}

1) A. Inoue: Bulk Amorphous Alloys, Materials Science Foundations, Vol. 4, (Trans Tech Publ., Zürich, 1998).

2) W. L. Johnson: MRS Bulletin 24 (1999) 2.

3) A. Peker and W. L. Johnson: Appl. Phys. Lett. 63 (1993) 2342.

4) A. Inoue, N. Nishiyama and T. Matsuda: Mater. Trans., JIM 37 (1996) 181.

5) T. Masumoto: Sci. Rep. RITU A39 (1994) 91.

6) M.-P. Macht, V. Naundorf, P. Fielitz, J. Rüsing, Th. Zumkley and G. Frohberg: Mater. Sci. Eng. A 304-306 (2001) 656.

7) C. C. Hays, C. P. Kim and W. L. Johnson: Appl. Phys. Lett. 75 (1999) 1089.

8) A. Wiedenmann, U. Keiderling, M.-P. Macht and H. Wollenberger: Mater. Sci. Forum 225-227 (1996) 71.

9) A. Wiedenmann and J. M. Liu: Solid State Comm. 100 (1996) 331.

10) S. Schneider, P. Thiagarajan, U. Geyer and W. L. Johnson: in MRS Symp. Proc Vol. 455 (MRS Pittsburgh, PA, USA, 1997) p. 295.

11) J. F. Löffler, P. Thiyagarajan and W. L. Johnson: J. Appl. Cryst. 33 (2000) 500

12) J. Schroers, R. Busch, A. Masuhr and W. L. Johnson: J. Non-Cryst. Solids. 250-252 (1999) 699.

13) M.-P. Macht, N. Wanderka, A. Wiedenmann, H. Wollenberger, Q. Wei, S. Klose, A. Sagel and H.-J. Fecht: in MRS Symp. Proc. Vol. 398, (MRS Pittsburgh, PA., USA, 1996) 375.

14) A. Hoell, F. Bley, A. Wiedenmann, J. P. Simon, A. Mazuelas and P. Boesicke: Scr. Mater. 44 (2001) 2335.

15) M.-P. Macht, V. Naundorf, P. Fielitz, J. Rüsing, E. Budke and G. Frohberg: Mater. Sci. Forum 343-346 (2000) 140.

16) M. P. Macht, N. Wanderka, Q. Wei, I. Sieber and N. Deyneka: Mater. Sci. Eng. A 304-306 (2001) 701.

17) T. A. Waniuk, J. Schroers and W. L. Johnson: Appl. Phys. Lett. 78 (2001) 1213.

18) Th. Zumkley, V. Naundorf and M.-P. Macht: Z. Metallkd. 91 (2001) 901.

19) N. Wanderka, Q. Wei, I. Sieber, U. Czubayko and M.-P. Macht: J.
Metastable and Nanocrystalline Materials 2-6 (1999) 369.

20) M.-P. Macht, N. Wanderka, I. Sieber and Q. Wei: in Materials Development and Processing-Bulk Amorphous Materials, Undercooling and Powder Metallurgy, EUROMAT99-Vol. 8 (Wiley-VCH, Weinheim, 2000) p. 10.

21) K. Tyagi, M.-P. Macht and V. Naundorf: Acta Metal. Mater. 39 (1991) 609.

22) M.-P. Macht and V. Naundorf: J. Appl. Phys. 53 (1982) 7551.

23) M.-P. Macht, R. Willecke and V. Naundorf: Nucl. Instr. Meth. Phys. Res. B43 (1989) 507.

24) Th. Zumkley, M.-P. Macht, V. Naundorf, J. Rüsing and G. Frohberg: Mater. Sci. Forum 343-346 (2000) 135.

25) Th. Zumkley, V. Naundorf, M.-P. Macht and G. Frohberg: Scr. Mater. 45 (2001) 471.

26) J. Horvath and H. Mehrer: Crys. Latt. Def. and Amorph. Mat. 13 (1986) 1.

27) Th. Zumkley, V. Naundorf, M.-P. Macht and G. Frohberg: Mater. Sci. Forum 386-388 (2002) 65-70.

28) R. Gerling, F. P. Schimansky and R. Wagner: Acta Metall. 35 (1987) 1001.

29) C. Nagel, K. Rätzke, E. Schmidke, J. Wolff, U. Geyer and F. Faupel: Phys. Rev. B 57 (1998) 224.

30) N. Wanderka, M.-P. Macht, M. Seidel, S. Mechler, K. Stahl and J. Z. Jiang: Appl. Phys. Lett. 77 (2000) 3935.

31) Th. Zumkley, V. Naundorf, M.-P. Macht and G. Frohberg: Defect and Diff. Forum 194-199 (2001) 801.

32) M.-P. Macht, N. Wanderka, A. Wiedenmann, H. Wollenberger, Q. Wei, H. J. Fecht and S. G. Klose: Mater. Sci. Forum 225-227 (1996) 65.

33) M. Miller: Mater. Sci. Eng. A 250 (1998) 133.

34) J.-M. Liu, A. Wiedenmann, U. Gerold and H. Wollenberger: Mater. Sci. Forum 235-238 (1997) 523.

35) N. Wanderka, Q. Wei, R. Dole, M. Jenkins, S. Friedrich, M.-P. Macht and H. Wollenberger: Mater. Sci. Forum 269-272 (1998) 773.

36) F. Faupel: Phys. Status Solidi A 134 (1992) 9.

37) P. Shewman: Diffusion in Solids, (Mc Graw-Hill, New York, 1963).

38) V. Naundorf, M.-P. Macht, A. S. Bakai and N. Lazarev: J. Non-Cryst. Solids 224 (1998) 122.

39) K. Knorr, M.-P. Macht and H. Mehrer: in Materials Development and Processing-Bulk-Amorphous Materials, Undercooling and Powder Metallurgy, EUROMAT99-Vol. 8 (Wiley-VCH, Weinheim, 2000) p. 22.

40) H. Nakajima, W. Sprengel and K. Nonoka: Defect and Diff. Forum 143147 (1997) 803.

41) H. Nakajima, T. Kojima, T. Zumkley, N. Nishiyama and A. Inoue: Proc. Int. Conf. on Solid-Solid Phase Transformations ' 99 (JIMIC-3) eds. by M. Koiwa, K. Otsuka and T. Miyazaki (Japan Inst. Metals, 1999) p. 441.

42) Th. Zumkley et al., to be published.

43) U. Geyer, W. L. Johnson, S. Schneider, Y. Qiu, T. A. Tombrello and M.-P. Macht: Appl. Phys. Lett. 69 (1996) 2492.

44) P. Tang, U. Geyer, R. Busch, W. L. Johnson and Y. Wu: Nature 402 (1999) 160

45) D. Srolovitz, T. Egami and V. Vitek: Phys. Rev. B 24 (1981) 6936. 